\title{
Controllable Preparation and the Tribological Properties of Bimetal Oxide $\mathrm{Zn}_{\mathbf{x}} \mathrm{Ti}_{\mathbf{y}} \mathrm{O}_{z}$
}

\author{
Wangbo Cao ${ }^{1, *}$, Dongqiang $\mathrm{Gao}^{1}$, Rui Wang ${ }^{1}$ \\ ${ }^{1}$ College of Mechanical and Electrical Engineering, Shaanxi University of Science and Technology, Xi'an 710021, PR China
}

\begin{abstract}
The bimetallic oxide films with different contents of $\mathrm{Zn}$ and $\mathrm{Ti}$ were prepared by magnetron sputtering and the films were annealed at $600^{\circ} \mathrm{C}$. The relationship between the structure and properties with different content of elements before and after annealed was comprehensively analyzed. It was found that with the decrease of $\mathrm{Zn}$ content, the number of the nuclear inside the film increased and the surface became denser. Therefore, the hardness and bonding strength gradually increased. The friction coefficient and the wear rate of the film were 0.154 and $7.4 \times 10^{-6} \mathrm{~mm}^{3} / \mathrm{N} \cdot \mathrm{m}$ respectively, due to the formation of $\mathrm{ZnTiO}_{3}$ and $\mathrm{ZnO}$ composite phases with lubricity on the surface.
\end{abstract}

\section{Introduction}

With the rapid development of high-tech industries such as aviation, aerospace, and nuclear power, more and more urgent demands have been put forward for new lubricating materials with long service life in a wide temperature range ${ }^{[1-5]}$. To achieve continuous lubrication from room-temperature (RT) to high temperature, Babinski et al. ${ }^{[6]}$ of the United States Air Force Research Office (AFRL) first proposed the concept of temperature "adaptive" design, in which the ternary oxide high-temperature lubricant is generated by the high-temperature tribological chemical reaction of the low temperature lubricating phases or the low-temperature lubricating phase and the matrix ${ }^{[7-9]}$. For example, $\mathrm{MoS}_{2}$ and $\mathrm{PbO}$ in the $\mathrm{MoS}_{2} / \mathrm{PbO}$ composite film all could play a role of lubricating from RT to medium temperature. In the high temperature, $\mathrm{PbMoO}_{4}$ lubricating phase generates by tribochemical reaction of the low temperature lubricants. Therefore, the $\mathrm{MoS}_{2} / \mathrm{PbO}$ composite film could provide continuous lubrication from RT to $700^{\circ} \mathrm{C}$. However, the mechanical properties of low temperature lubricating phases such as $\mathrm{MoS}_{2}$ and $\mathrm{PbO}$ are too poor to provide the sufficient bearing capacity during service. According to this concept, the researchers combined $\mathrm{Ag}$ to transition Metal (TM) nitride hard film, such as $\mathrm{Mo}_{2} \mathrm{~N} / \mathrm{Ag}, \mathrm{VN} / \mathrm{Ag}, \mathrm{NbN} / \mathrm{Ag}$ and $\mathrm{TaN} / \mathrm{Ag}^{[10-13]}$. Soft metal Ag plays a lubricating role in low and medium temperature due to the low shear force. At high temperature, $\mathrm{TMO}_{\mathrm{x}}$ react with $\mathrm{Ag}$ to generate $\operatorname{AgTM}_{x} \mathrm{O}_{y}$. Due to the weak bond of $\mathrm{Ag}-\mathrm{O}, \mathrm{AgTM}_{\mathrm{x}} \mathrm{O}_{\mathrm{y}}$ plays a good lubricating role at high temperature ${ }^{[14-18]}$.

The composites designed by the concept of temperature "adaptive" could provide continuous lubrication in a wide temperature, but the lubricants operated in low temperature range would fail at high temperature. Ageh et al. ${ }^{[19]}$ reported that the $\mathrm{ZnTiO}_{3}$ film with a structure of (104) crystal plane preferential growth has excellent tribological properties in the wide temperature range. The study found that the $\mathrm{Zn}_{\mathrm{x}} \mathrm{Ti}_{\mathrm{y}} \mathrm{O}_{\mathrm{z}}$ thin film was annealed at $550^{\circ} \mathrm{C}$ to form a $\mathrm{ZnTiO}_{3}$ structure with (104) preferential growth on the crystal plane. When the friction proceeds along the direction of (104) crystal plane, the surface defects in (104) crystal planes significantly reduce the friction coefficient and wear rate (The friction coefficient is 0.12 , the wear rate is $\left.10^{-7} \mathrm{~mm}^{3} / \mathrm{N} \cdot \mathrm{m}\right)$. However, there are few studies on the relationship of the structure and lubricity of the bimetallic oxides.

In order to research the relationship of crystal structure and lubricity of $\mathrm{Zn}_{\mathrm{x}} \mathrm{Ti}_{\mathrm{y}} \mathrm{O}_{\mathrm{z}}, \mathrm{Zn}_{\mathrm{x}} \mathrm{Ti}_{\mathrm{y}} \mathrm{O}_{\mathrm{z}}$ films were prepared by physical vapor deposition techniques in this work, and then the effects of the crystal structure on the mechanical and tribological properties was investigated.

\section{Experimental procedure}

\subsection{Film Preparation}

Bimetal Oxide $\mathrm{Zn}_{\mathrm{x}} \mathrm{Ti}_{\mathrm{y}} \mathrm{O}_{\mathrm{z}}$ films were deposited on $\mathrm{Ni}$-based high temperature alloy (Inconel 718, polished to a roughness (Ra) of 20 to $30 \mathrm{~nm}$ ) using a reactive magnetron sputtering system. The schematic diagram of the magnetron sputtering is shown in Fig.1. Prior to the deposition, mirror polished Inconel 718 alloys were ultrasonically cleaned in acetone (99.5\%) and ethanol, and then mounted on the substrate holder in the vacuum chamber, where samples A and B were close to the zinc

\footnotetext{
*The corresponding author's e-mail address: 1805029@sust.edu.cn
} 
target and samples $\mathrm{C}$ and $\mathrm{D}$ were close to the titanium target. First, the vacuum chamber air pressure was pumped to $10^{-3} \mathrm{~Pa}$, and the high-purity argon was fed to make the chamber air pressure reach $0.5 \mathrm{~Pa}$. Subsequently, set the pulse bias voltage to $-100 \mathrm{~V}$. DC power supply is used to control zinc target, while RF power supply is used to control titanium target. Adjust the current value and power value respectively, and keep the air pressure in the vacuum chamber between $0.4 \mathrm{~Pa}$ and $0.5 \mathrm{~Pa}$.Oxygen is then pumped in to adjust the flow ratio of argon to oxygen. Argon was used as a protective atmosphere, and oxygen was used as a reaction gas to deposit the film for 90 minutes. The specific preparation parameters are shown in Table 1.

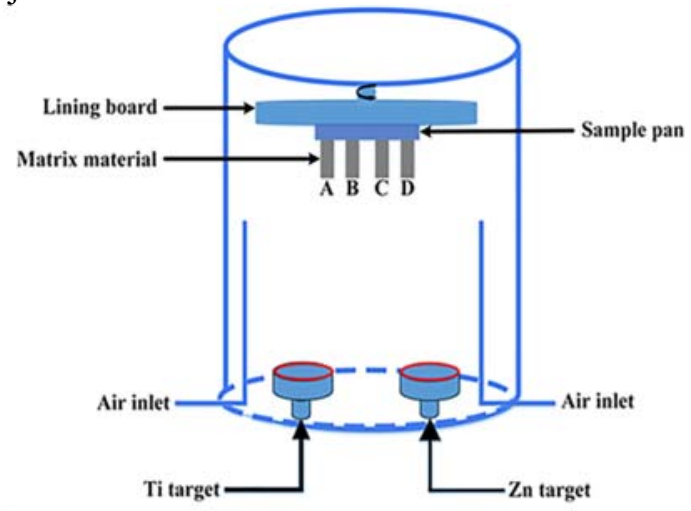

Fig. 1. The schematic diagram of magnetron sputtering

Table 1 Detail deposition parameters of bimetal oxide $\mathrm{Zn}_{\mathrm{x}} \mathrm{Ti}_{\mathrm{y}} \mathrm{O}_{\mathrm{z}}$ films deposited by magnetron sputtering system.

\begin{tabular}{ll}
\hline Parameter & Value \\
\hline Working pressure $(\mathrm{Pa})$ & 0.5 \\
$\mathrm{O}_{2}$ :Ar ratio & $40: 80$ \\
Sputtering current of Zn target(A) & 0.04 \\
Power of Ti target(W) & 75 \\
Bias voltage(-V) & 100 \\
\hline
\end{tabular}

\subsection{Annealing treatment}

Bimetal Oxide $\mathrm{Zn}_{\mathrm{x}} \mathrm{Ti}_{\mathrm{y}} \mathrm{O}_{\mathrm{z}}$ coatings were annealed at $600{ }^{\circ} \mathrm{C}$ ${ }^{[19]}$ in air with a heating rate of $6{ }^{\circ} \mathrm{C} / \mathrm{min}$ and holding time of $2 \mathrm{~h}$, and then cooled in the furnace naturally. Originally, the deposited films were labeled A, B, C, and D. Following the annealing, they were labeled as A1, B1, $\mathrm{C} 1$, and D1.

\subsection{Film Characterization}

The phase composition was identified with a Philips X'Pert-MRD X-ray diffractometer (XRD; $40 \mathrm{kV}, 30 \mathrm{~mA}$, $\mathrm{Cu}-\mathrm{K} \alpha$ radiation; scanning within $\left.2 \theta=20-80^{\circ}\right)^{[20]}$. The grain size of the films was calculated by using DebyeScherrer's formula and Jade analysis software. Surface morphologies of the bimetal oxide $\mathrm{Zn}_{\mathrm{x}} \mathrm{Ti}_{\mathrm{y}} \mathrm{O}_{\mathrm{z}}$ films were observed with a scanning electron microscope (SEM; JSM-5600LV). The energy dispersive spectrometer (EDS) attached to the SEM was used to determine the element composition. The hardness of the bimetal oxide $\mathrm{Zn}_{\mathrm{x}} \mathrm{Ti}_{\mathrm{y}} \mathrm{O}_{\mathrm{z}}$ films was determined using a CSM Nano-indentation Tester in continuous multi-cycle mode $(5-50 \mathrm{mN})$. The scratch tester was used to detect the film-base bonding force of the material. The friction coefficient of the bimetal oxide $\mathrm{Zn}_{\mathrm{x}} \mathrm{Ti}_{\mathrm{y}} \mathrm{O}_{\mathrm{z}}$ films was measured under dry conditions were investigated using a wear testing apparatus (CSM) against $\mathrm{Al}_{2} \mathrm{O}_{3}$ balls at an ambient temperature ranging from $20{ }^{\circ} \mathrm{C}$ to $25^{\circ} \mathrm{C}$ and a relative humidity of $50 \pm 5 \%$. The worn surface morphology was observed by SEM, and the wear rate was measured with the $3 \mathrm{D}$ profiler.

\section{Results and discussion}

\subsection{Structural analysis of $\mathrm{Zn}_{x} \mathrm{Ti}_{y} \mathrm{O}_{z}$ thin films}

The element compositions carried out by EDS are displayed in Table. 2. Evidently, the content of the $\mathrm{Zn}$ element progressively decreases from A to D, contrarily, the Ti content increases. The $\mathrm{Zn} / \mathrm{Ti}$ ratios of the samples are $14.74,10.24,4.93$, and 2.22, respectively (A to D). Following the annealing process, the $\mathrm{Zn}$ content progressively decreased in all samples (A1 to D1), while the Ti content increased progressively in all samples (A1 to D1). Following annealing, the $\mathrm{Zn} / \mathrm{Ti}$ ratios of the samples are 14.21, 6.21, 4.02, and 1.99, respectively (A1 to D1). According to the Ellingham diagram ${ }^{[21]}$, the diffusion rate of $\mathrm{Ti}$ is higher at a temperature of $600{ }^{\circ} \mathrm{C}$. Therefore, following the annealing at $600{ }^{\circ} \mathrm{C}$, the $\mathrm{Zn} / \mathrm{Ti}$ ratio of the films has decreased in comparison to the original films. 
Table 2 EDS analysis result of the as-deposited films and the annealed films.

\begin{tabular}{cccccccc}
\hline $\begin{array}{c}\text { Element/ } \\
\text { (wt. \%) }\end{array}$ & $\mathrm{Zn}$ & $\mathrm{Ti}$ & $\mathrm{C}$ & $\mathrm{O}$ & $\mathrm{Fe}$ & $\mathrm{Cr}$ & $\mathrm{Ni}$ \\
\hline $\mathrm{A}$ & 56.17 & 3.81 & 6.38 & 14.83 & 4.43 & 4.18 & 10.2 \\
$\mathrm{~B}$ & 52.85 & 5.16 & 7.16 & 12.84 & 5.56 & 5.52 & 10.91 \\
$\mathrm{C}$ & 40.17 & 8.15 & 8.64 & 13.31 & 8.52 & 8.14 & 13.07 \\
$\mathrm{D}$ & 28.01 & 12.59 & 8.63 & 12.13 & 9.09 & 10.05 & 19.5 \\
$\mathrm{~A} 1$ & 58.27 & 4.1 & 6.71 & 14.94 & 3.97 & 3.59 & 8.42 \\
$\mathrm{~B} 1$ & 52.58 & 8.47 & 6.7 & 12.84 & 4.71 & 4.6 & 10.1 \\
$\mathrm{C} 1$ & 40.27 & 10.01 & 6.79 & 12.12 & 8.08 & 8.26 & 14.47 \\
$\mathrm{D} 1$ & 28.49 & 14.31 & 10.43 & 12.84 & 8.1 & 8.26 & 17.57 \\
\hline
\end{tabular}

The XRD patterns of the as-deposited films and annealed films are shown in Fig. 2. In relation to the as-deposited films, Fig. 2 (a) shows that compared to sample B, sample A has a higher crystalline. Simultaneously, the surface of the film of sample A is composed of the composite phase of $\mathrm{ZnTiO}_{3}$ and $\mathrm{ZnO}$. Meanwhile, the surface of the film of sample B produces $\mathrm{Zn}_{2} \mathrm{TiO}_{4}, \mathrm{ZnO}$, and $\mathrm{TiO}_{2}$ phases. The spectrum of sample $\mathrm{C}$ contains only one peak with less intensity. During the deposition process, the film is primarily in the amorphous state, a few grains are dispersed in the amorphous. The absence of diffraction peaks in the spectrogram of sample $\mathrm{D}$ indicates that during the

Table3 The grain size of bimetal oxide $\mathrm{Zn}_{\mathrm{x}} \mathrm{Ti}_{\mathrm{y}} \mathrm{O}_{\mathrm{z}}$ films before and after annealing.

\begin{tabular}{cccc}
\hline Samples & Grain size/nm & Samples & Grain size $/ \mathrm{nm}$ \\
\hline A & 12.8 & A1 & 13.16 \\
B & 10.32 & B1 & 10.59 \\
C & - & C1 & 9.16 \\
D & - & D1 & 8.29 \\
\hline
\end{tabular}

Owing to the strong reactivity of $\mathrm{Ti}$ element to Oxygen when annealing at $600{ }^{\circ} \mathrm{C}$, the $\mathrm{Ti}$ element diffused firstly. Fig.2 (b) shows that the peak intensity of the samples A1 and B1 increases. Moreover, compared to the samples of A and B, the crystallinity of the samples $\mathrm{A} 1$ and B1 are higher. The samples of A1 comprises of $\mathrm{ZnTiO}_{3}$ and $\mathrm{ZnO}$ composite phase. The sample $\mathrm{B} 1$ comprises of $\mathrm{Zn}_{2} \mathrm{TiO}_{4}$ and $\mathrm{ZnO}$ composite phase. In addition to eliminating the internal stress of the films, deposition process, the atomic arrangement was disordered. Moreover, there aren't any stable nucleation and amorphous structure. Furthermore, during the deposition process, a current of $0.04 \mathrm{~A}$ with a power of $15 \mathrm{~W}$ was used on the Zinc target. Meanwhile, the power of the Titanium target was $75 \mathrm{~W}$. Specifically, there are a higher number of excited Titanium atoms than Zinc atoms. Since the particles are unable to reach the surface of the C and D samples to migrate and form low crystallinity crystals, or even disordered amorphous structures, the deposition rate of Titanium atoms to progressively increase through samples A to D.

annealing also reorganizes the disorganized structures of the samples of C and D, the structure gradually becomes regular and ordered. However, the diffraction peaks of the samples of $\mathrm{C} 1$ and D1 are wide and low. So, the samples of $\mathrm{C} 1$ and D1 have a particularly low degree of crystallinity. The surface of the samples of $\mathrm{Cl}$ is composed of $\mathrm{Zn}_{4} \mathrm{TiO}_{6}$ and $\mathrm{Ti}_{3} \mathrm{O}_{5}$ composite phases. Meanwhile, the surface of the samples of D1 is composed of $\mathrm{Zn}_{4} \mathrm{TiO}_{6}$ and $\mathrm{Ti}_{3} \mathrm{O}_{5}$ composite phases.
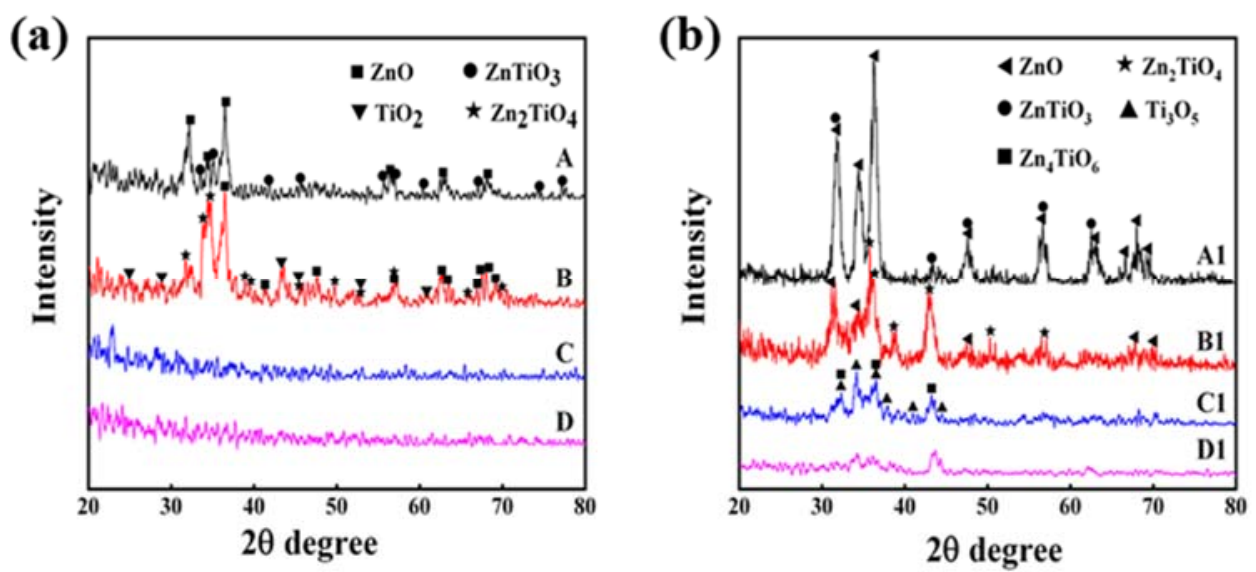

Fig. 2. XRD patterns of (a) as-deposited films, (b) the annealed films

Based on the half-width of the characteristic peaks of the XRD patterns shown in Fig. 2, the grain size of the 
films before and after annealing are obtained by using the Scherrer formula ${ }^{[22]}$. The grain size of the bimetal oxide $\mathrm{Zn}_{\mathrm{x}} \mathrm{Ti}_{\mathrm{y}} \mathrm{O}_{\mathrm{z}}$ films before and after annealing are displayed in Table.3. The grain size of the samples of $\mathrm{C}$ and $\mathrm{D}$ are not calculated, because the samples of $\mathrm{C}$ is primarily amorphous, with a small number of grains on the surface, and thin-film $\mathrm{D}$ is of a disorderly amorphous state. As the content of $\mathrm{Zn}$ increases, the grain size of the films decreases. After annealing, the grain size of the films increased slightly, and the grain size decreases as the content of $\mathrm{Zn}$ decreases.

\subsection{Morphology analysis of $\mathrm{Zn}_{x} \mathrm{Til}_{y} \mathrm{O}_{z}$ thin films}

The surface morphology of the as-deposited films containing different contents of $\mathrm{Zn}$ and $\mathrm{Ti}$ is shown in Fig. 3. It illuminate that the thin film deposited by magnetron sputtering technology is uniform without defects such as large particles and droplets. This is due to the condensing of gas-phase atoms attached to the surface during the formation of the film, which forms atomic pairs and the formation and growth of nuclei. The process of depositing the bimetallic oxide films may initially cause samples A and B to form stable nuclei during the nucleation process. The surrounding Titanium atoms and Zinc atoms are adsorbed by the Titanium cores, forming separate bonds. The islands expand and merge into thin films. Titanium atoms form the core of the bimetallic oxide films. Therefore, as the number of Zinc atoms adsorbed around the formed Titanium stable core increases, the crystal grains become coarser, making the surface rougher. The large crystal grains of film A and B can be explained this way. A small number of grains are dispersed on surface $\mathrm{C}$ of the film, yet, the amorphous phase is the primary form. The surface D of the film is smooth, and under the magnification of the electron microscope, there was no obvious grain on surface D. This could be attributed to the disordered atomic arrangement exhibited, and the lack of crystal nucleus formation. Additionally, the inside of the film is an amorphous structure. So, the surface of the film is very dense. The particles on the surface of the film are getting finer and increasingly uniform, increasing the smoothness and density of the structure as the content of $\mathrm{Zn}$ in the original film decreases.
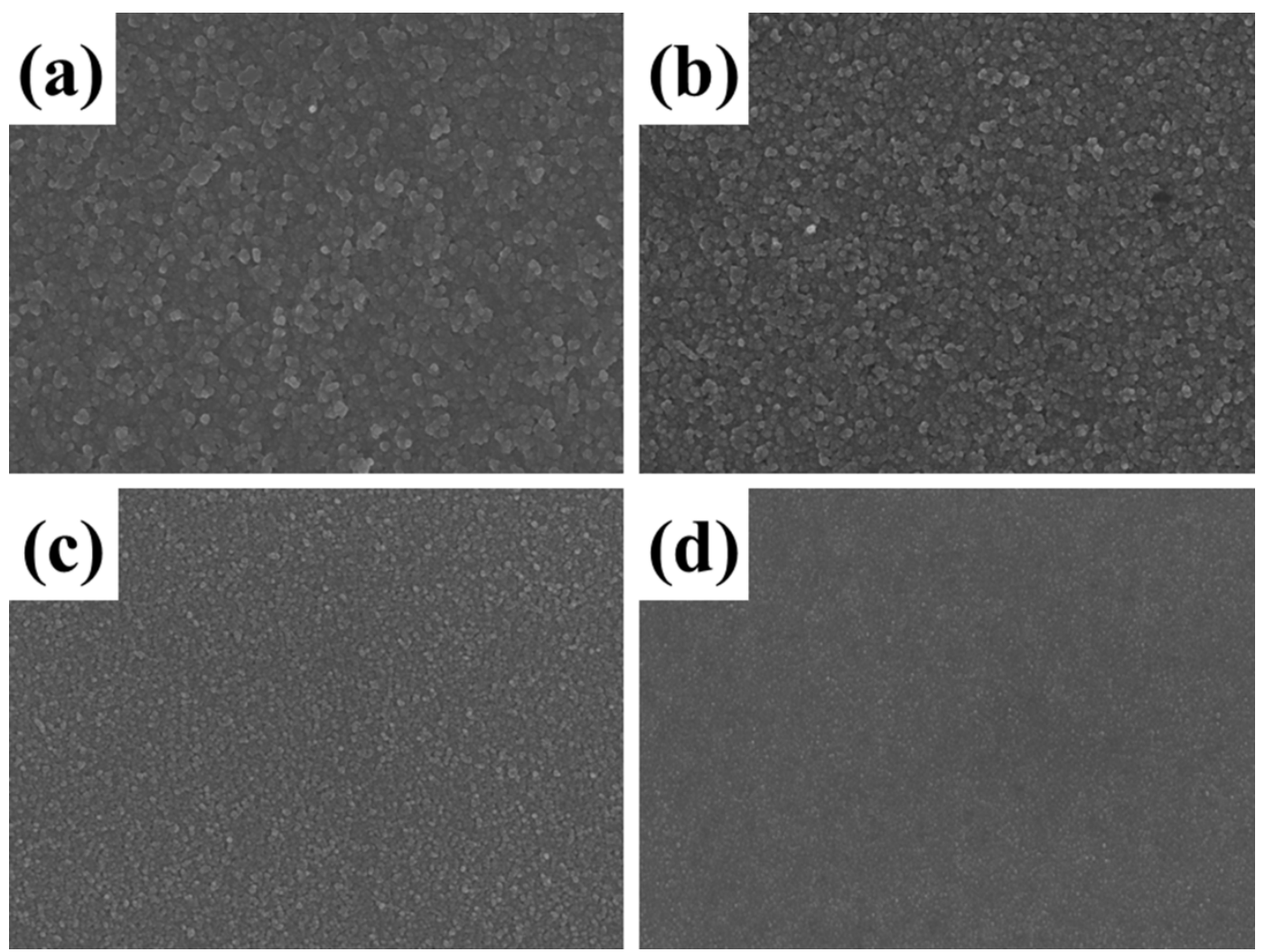

Fig. 3. Surface morphology of the as-deposited films (a) the samples of A, (b)the samples of B, (c)the samples of $\mathrm{C},(\mathrm{d})$ the samples of $\mathrm{D}$

The surface morphology of the films annealed at $600{ }^{\circ} \mathrm{C}$ is shown in Fig. 4. The grains of the film have been rearranged in the annealing process. Although there are more Ti nuclei, small crystal nuclei will grow at higher temperatures. Therefore, the grains of $\mathrm{A} 1$ and $\mathrm{B} 1$ are slightly increased compared to the original film and the spacing between the grains is increased, resulting in the structure becoming inhomogeneous and uniform. At high temperatures, the structure of $\mathrm{C}$ and $\mathrm{D}$ begin to crystallize, resulting in the growth of grain size. However, $\mathrm{C} 1$ has a higher content of $\mathrm{Zn}$ than D1, therefore, the surface of D1 is more compact. As the content of $\mathrm{Zn}$ in the annealed film decreases, the grain size reduces, making the surface smoother and denser.

\subsection{Mechanical properties of $\mathrm{Zn}_{x} \mathrm{Ti}_{y} \mathrm{O}_{z}$ thin films}

The mechanical properties of the film are significantly 
influenced by the different $\mathrm{Zn}_{\mathrm{x}} \mathrm{Ti}_{\mathrm{y}} \mathrm{O}_{\mathrm{z}}$ structures before and after annealing at $600{ }^{\circ} \mathrm{C}$. The hardness curve of the film before and after the annealing process is shown in Fig. 5. The hardness of the samples is $302.8 \mathrm{HV}, 330.3$ $\mathrm{HV}, 398.1 \mathrm{HV}$, and 417.7 HV, respectively (A to D). In the original film, the hardness progressively increased as the content of $\mathrm{Zn}$ reduced. This is because the $\mathrm{Zn}_{\mathrm{x}} \mathrm{Ti}_{\mathrm{y}} \mathrm{O}_{\mathrm{z}}$ bimetal oxide film forms a stable nucleus with titanium atoms, while zinc atoms are adsorbed on the periphery of the crystal nucleus and grow into a thin film. When the content of $\mathrm{Zn}$ is $56.17 \%$, the number of stable nuclei formed is small due to the low content of $\mathrm{Ti}$ and the number of zinc atoms around the crystal nucleus is large. Therefore, the gap between the crystal grains is large, due to the large grain size of the film after nucleation growth, so the hardness of the film is the smallest. The number of $\mathrm{Zn}$ atoms around the crystal nucleus decreased when the content of $\mathrm{Zn}$ decreased to $52.85 \%$. Meanwhile, the grain size of the film decreased and the hardness increased slightly. As the content of $\mathrm{Zn}$ continues to decrease, the atoms in the film appear to be disorderly distributed without grain boundaries. Therefore, compared with crystalline thin films, they are more uniform and dense in structure and have excellent mechanical properties. The hardness of the film can be as high as $420 \mathrm{HV}$ when the contents of $\mathrm{Zn}$ and $\mathrm{Ti}$ are $28.01 \mathrm{wt} \%$ and $12.59 \mathrm{wt} \%$, Respectively.
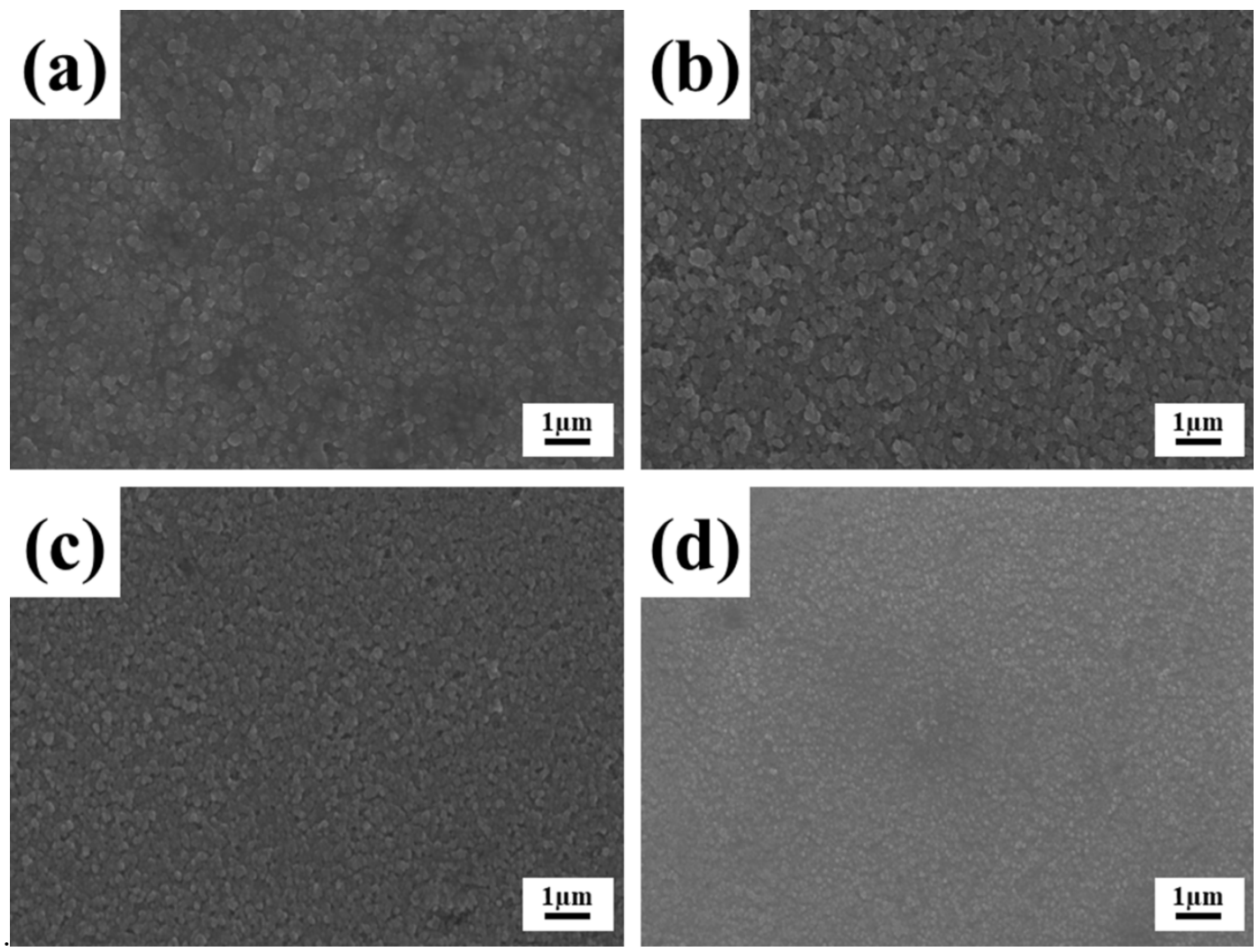

Fig. 4. Surface morphology of the annealed films (a)the samples of A, (b)the samples of B, (c)the samples of C, (d)the samples of D

The dotted line in Fig. 5 is the change curve of the hardness of the film with element content after annealing treatment at $600{ }^{\circ} \mathrm{C}$. After annealing, the hardness of the films are $254.6 \mathrm{HV}, 276.2 \mathrm{HV}, 356 \mathrm{HV}$, and $382.5 \mathrm{HV}$, respectively (A1 to D1). The gradual reduction in the $\mathrm{Zn}$ content is accompanied by a progressive increase in the hardness of the films. Moreover, the hardness of the films after annealing at a high temperature is lower than the hardness of the original films. After annealing at $600{ }^{\circ} \mathrm{C}$, the crystal grains within the film rearranges after gaining external energy. The rise in temperature causes the small crystal grains in the original film to grow, additionally, the crystallinity is higher, which releases the stress within the film. Resultantly, crystal grains having a stable structure in the crystal state become coarse, and the structure is loosened. The amorphous disordered films in metastable state gradually change to stable state after annealing at high temperature. Then, it starts to crystallize and the grains grow, but the crystallinity is very low. Consequently, the hardness of the thin films increases gradually as the content of $\mathrm{Zn}$ decreases after annealing. 


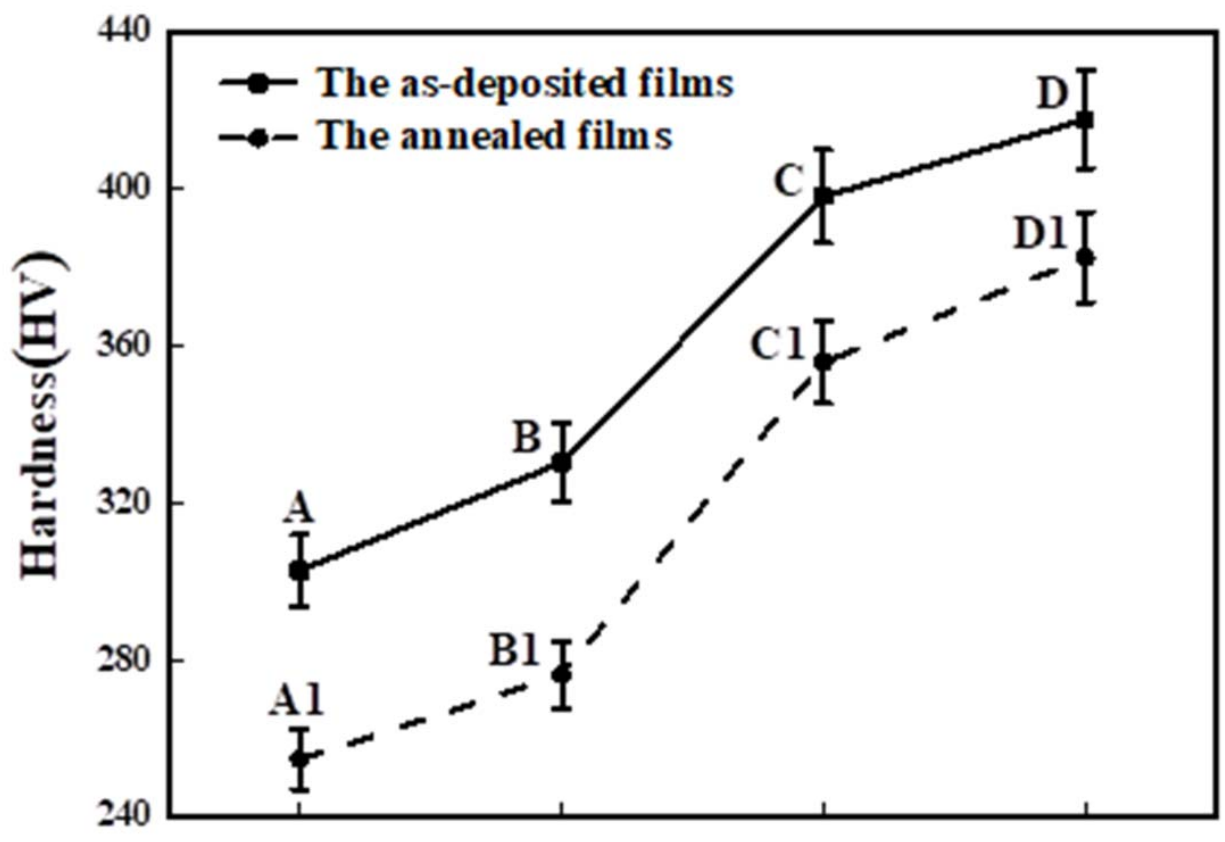

Fig. 5. The variation of hardness of as-deposited and annealed films

The quantitative analysis of the film base binding force of the films before and after annealing is shown in Fig. 6 and Fig. 7. $\mathrm{L}_{\mathrm{C} 1}$ corresponds to the minimum force which causes the dendritic cracks in the films. $\mathrm{L}_{\mathrm{C} 2}$ corresponds to the minimum force necessary to entirely detach the film from the substrate. Fig. 6 shows that $\mathrm{L}_{\mathrm{C} 1}$ of sample A to D are 7.7 N,5.2 N,6.4 N,10.3 N and $\mathrm{L}_{\mathrm{C} 2}$ are $20 \mathrm{~N}, 24.4 \mathrm{~N}, 27.2 \mathrm{~N}, 35.9 \mathrm{~N}$, respectively. Out of these, sample A has the highest content of Zinc. With the reduction of $\mathrm{Zn}$ content in the film, the minimum force required to cause partial peeling of the film initially decreases before rising again. Moreover, the film-based bonding force shows a progressively increasing trend. The reason for this is the increment in the number of titanium atomic nucleation in the film with the reduction in $\mathrm{Zn}$ content, resulting in the crystal grains to be more uniform. Owing to the extremely high deposition rate, the particles have no time to migrate to form an original film of amorphous shape. Due to the absence of grain boundaries, defects, etc., there is a high binding force. Therefore, as the $\mathrm{Zn}$ content decreases, the film-based binding force of the original thin film increases gradually.

The bonding force of the original film after annealing at high temperature is shown in Fig.7. $\mathrm{L}_{\mathrm{C} 1}$ and $\mathrm{L}_{\mathrm{C} 2}$ of sample $\mathrm{A} 1$ are $5.9 \mathrm{~N}$ and $13 \mathrm{~N}$, respectively. When the load is $5.9 \mathrm{~N}$, the crack will penetrate into the substrate, and the minimum force required for the film to completely peel is $13 \mathrm{~N}$. The $\mathrm{L}_{\mathrm{C} 1}$ of samples $\mathrm{B} 1$ to $\mathrm{D} 1$ are $7.7 \mathrm{~N}, 8.5 \mathrm{~N}$, and $11.5 \mathrm{~N}$, respectively. $\mathrm{L}_{\mathrm{C} 2}$ are $14.3 \mathrm{~N}$, $25.9 \mathrm{~N}$, and $18 \mathrm{~N}$, respectively. As the content of $\mathrm{Zn}$ decreases, the minimum force required to partially peeling off the film, and the minimum force required to completely peel off the film tend to steadily increase. Due to the annealing, samples A1 and B1 have mainly grown the small crystal nuclei formed in the original film. Then, the growth of the grains is rough and uneven, and ultimately, the composite phase is generated to reduce the density of the film. At high temperature, samples $\mathrm{C} 1$ and D1 crystallized from amorphous structure to an ordered structure. Crystal nuclei were formed in the film, and there was a growth in the grains. However, the high content of titanium in D1 and the denser structure creates a considerably high number of small crystal nuclei. Resultantly, the film-based binding force is improved. Therefore, as the content of $\mathrm{Zn}$ in the thin film decreases after annealing, the bonding strength of the film base increases. However, after annealing, the film-based bonding force of the film is slightly less than that of the original film. 


$\begin{array}{ccccc}0 & 10 & 20 & 30 & 40 \\ \longrightarrow & 1 & 1 & 1\end{array}$
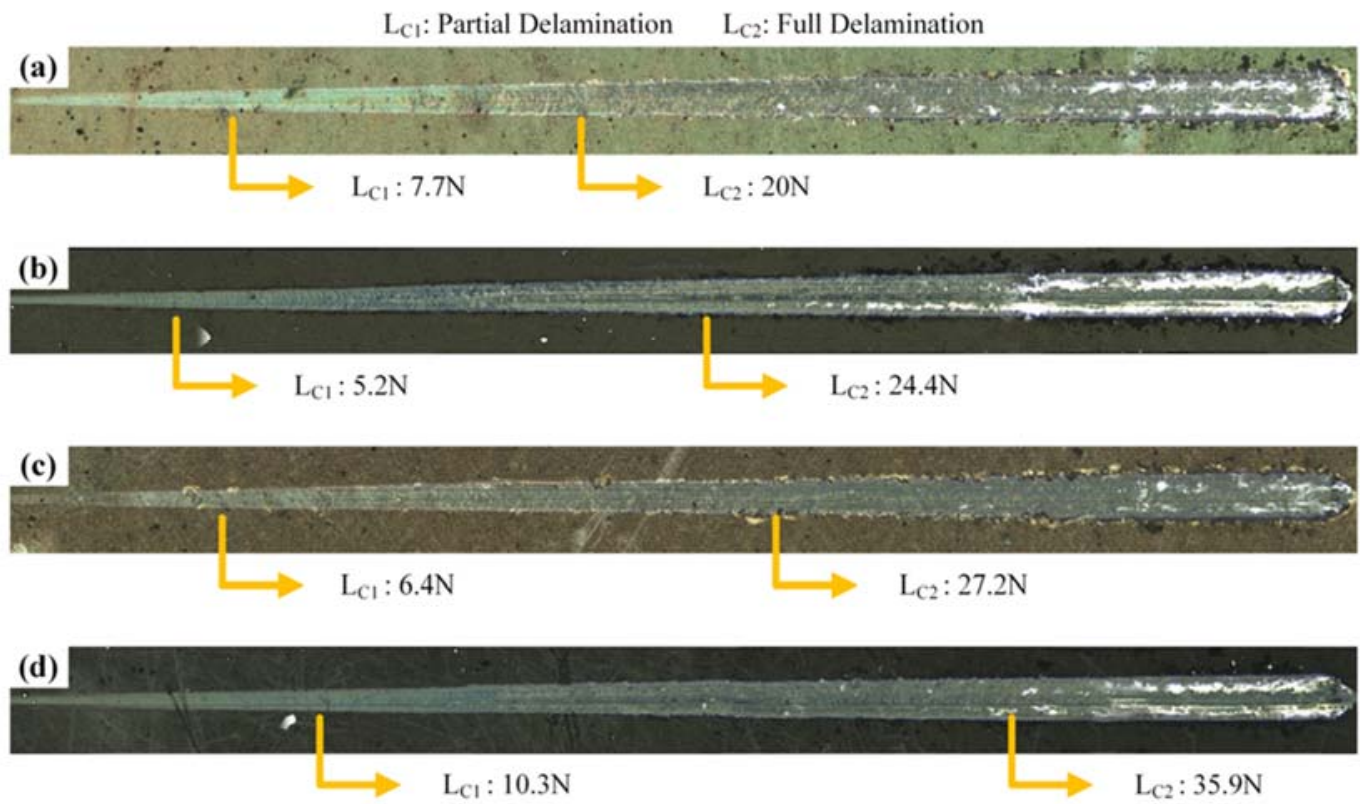

Fig. 6. The scratch test of as-deposited films

\begin{tabular}{ccccc}
0 & 10 & 20 & 30 & 40 \\
$\perp$ & 1 & $\mid$ & 1 \\
\hline
\end{tabular}
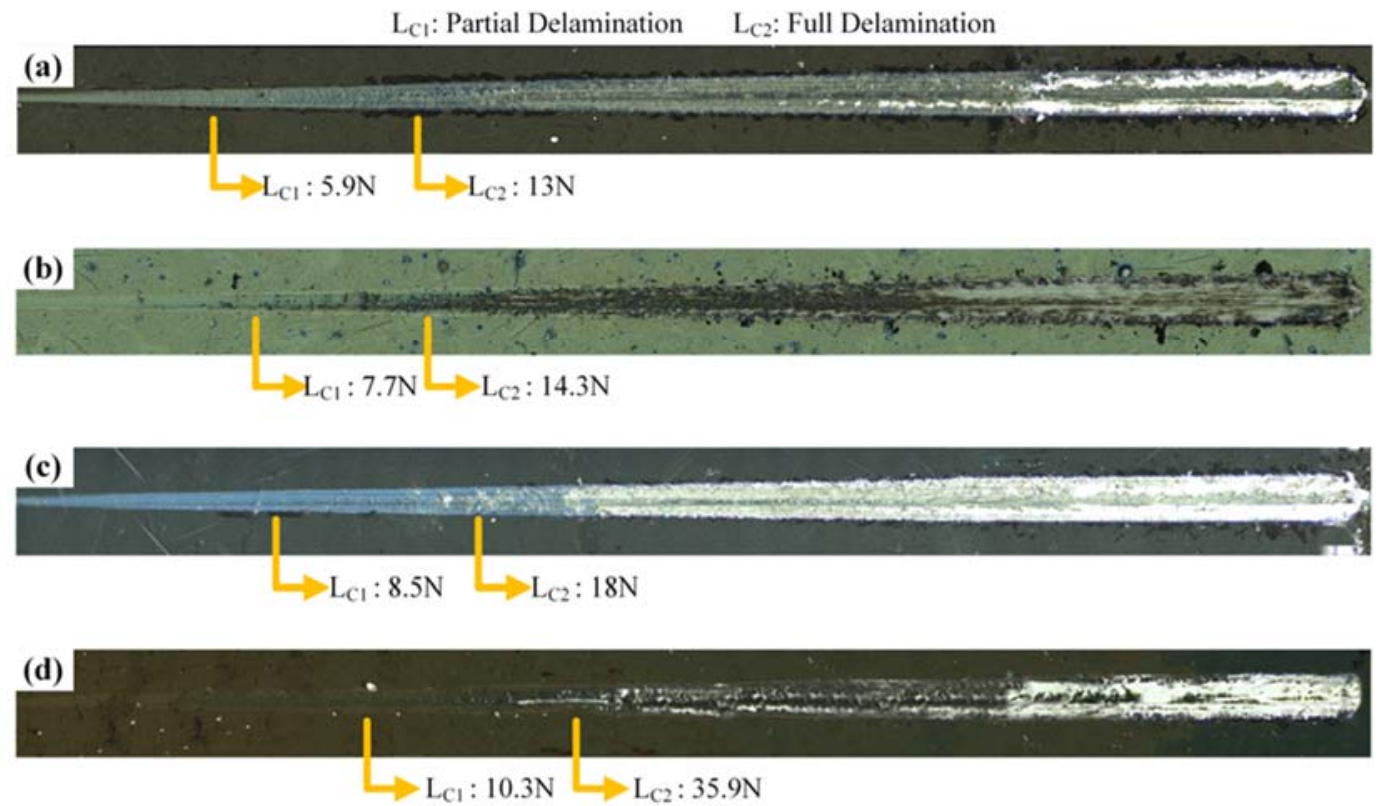

Fig. 7. The scratch test of annealed films

\subsection{Effect of different $\mathrm{Zn}$ and $\mathrm{Ti}$ content on Tribological Properties of films}

The relationship curve of the friction factor of the original film with the change of the grinding process is shown in Fig. 8. The wear rates of the films before and after annealing are displayed in Table. 4. The average friction factor and wear rate of sample $\mathrm{A}$ with the $\mathrm{Zn}$ content of $56.17 \%$ and the Ti content of $3.81 \%$ is 0.154 and $7.4 \times 10^{-6} \mathrm{~mm}^{3} / \mathrm{N} \cdot \mathrm{m}$, respectively. As the sliding distance increases, the friction factor also increases gradually. This could be due to the smaller hardness of sample A compared to the alumina ceramics, and the film will most probably fall off during friction to generate a large amount of abrasive debris. Hence, as the grinding process increases, the friction factor also continues to rise. Within a sliding distance of $100 \mathrm{~m}$, sample A can maintain a low friction factor and wear rate. Most likely, $\mathrm{ZnTiO}_{3}$ and $\mathrm{ZnO}$ composite phases would be formed on the film's surface. It has been demonstrated that, during 
the sliding process, the $\mathrm{ZnTiO}_{3}$ phase with defect structure makes the sliding direction parallel to the (104) crystal plane ${ }^{[19,23]}$. The speed of the self-adjusting mode is generated within the film to drastically reduce both friction factor and wear rate. For a $\mathrm{Zn}$ content of $52.85 \%$ and the Ti content of $5.16 \%$, the friction coefficient of sample B stabilized at approximately 0.2 in $6 \mathrm{~m}$. As the grinding distance increases, the friction coefficient increases rapidly. When the sliding distance exceeds $18 \mathrm{~m}$, the film may have been completely worn. In this sliding distance, the average friction factor is 0.46 , and the wear rate is approximately $1.8 \times 10^{-4} \mathrm{~mm}^{3} / \mathrm{N} \cdot \mathrm{m}$. Since the composite phase of $\mathrm{Zn}_{2} \mathrm{TiO}_{4}, \mathrm{ZnO}$ and $\mathrm{TiO}_{2}$ is formed on the surface of film $B$, they are unable to serve as an effective lubricant on the film ${ }^{[24]}$. With the decrease of
$\mathrm{Zn}$ content in the film and the increase of Ti content in the film, the friction factors of sample $\mathrm{C}$ and $\mathrm{D}$ have similar change rules with that of sample B. It is the phenomenon that the films are worn through as the sliding distance increases. However, after $10 \mathrm{~m}$, the friction factor of sample $\mathrm{C}$ increased significantly. The average friction factor is 0.31 and the wear rate is $2.5 \times 10^{-4} \mathrm{~mm}^{3} / \mathrm{N} \cdot \mathrm{m}$. After $16 \mathrm{~m}$, the friction factor of $\mathrm{D}$ increases sharply. The average friction factor and wear rate of $D$ is roughly 0.29 and $7.2 \times 10^{-5} \mathrm{~mm}^{3} / \mathrm{N} \cdot \mathrm{m}$, respectively. Since D has a denser surface structure than $\mathrm{C}$, the mechanical properties of $\mathrm{D}$ are better than $\mathrm{C}$. Therefore, prior to been worn out, film D can maintain a stable friction factor throughout a longer sliding distance. (a)

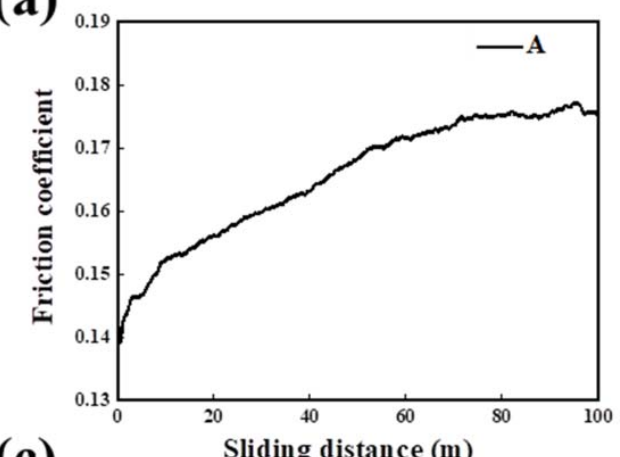

(c)

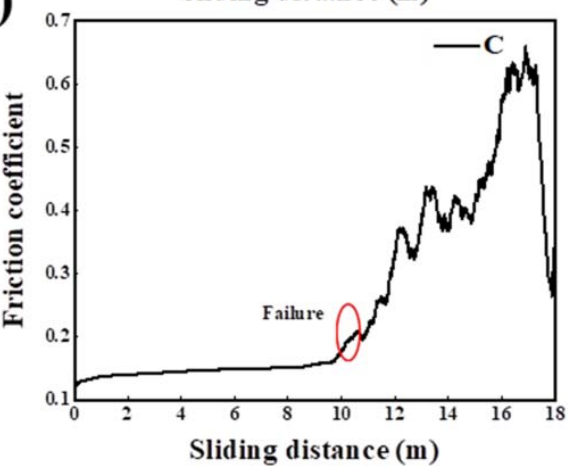

Fig. 8. Friction coefficient of as-deposited

The relationship between the friction coefficient and the sliding distance of the film after annealing is shown in Fig. 9. The average friction factor and wear rate of sample A1 are 0.16 and $7.2 \times 10^{-5} \mathrm{~mm}^{3} / \mathrm{N} \cdot \mathrm{m}$, respectively. Within a sliding distance of $65 \mathrm{~m}$, the average friction factor and wear rate of sample B1 are 0.41 and $9 \times 10^{-5}$ $\mathrm{mm}^{3} / \mathrm{N} \cdot \mathrm{m}$, respectively. Within a sliding distance of $50 \mathrm{~m}$, the average friction factor and wear rate of sample $\mathrm{C} 1$ are 0.67 and $7.4 \times 10^{-5} \mathrm{~mm}^{3} / \mathrm{N} \cdot \mathrm{m}$, respectively. Within a sliding distance of $6 \mathrm{~m}$, the average friction factor and wear rate of sample D1 are 0.35 and $2.2 \times 10^{-4} \mathrm{~mm}^{3} / \mathrm{N} \cdot \mathrm{m}$, respectively. Following the annealing process, the friction factor of A1 increases with the increase of the grinding process, and then it tends to be stable. This can be attributed to the less dense surface structure of the film, which was caused by the annealing process. So, when rubbing starts, the surface is in the run-in stage. As (b)

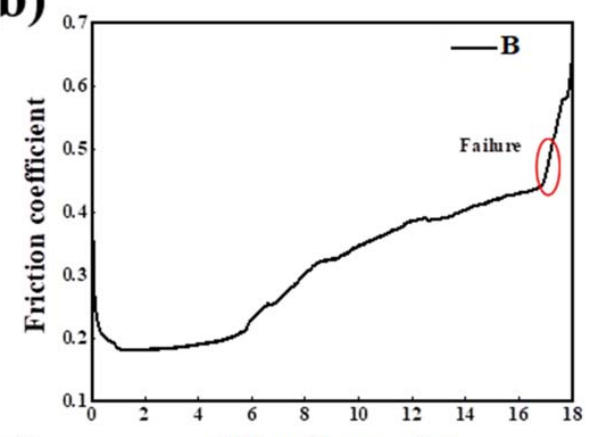

(d)

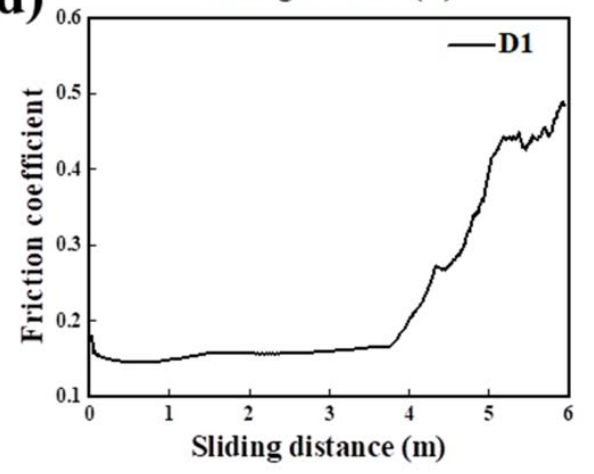

films as a function of sliding distance

the sliding distance increases, the flaking debris falls into the pit. When this occurs, the $\mathrm{ZnTiO}_{3}$ phase serves as a lubricator. Consequently, the friction factor tends to be stable. In comparison with sample B, after the annealing process, the sliding distance of sample B1 is increased, additionally, the friction factor is also significantly reduced. This could be attributed to the formation of the composite phase of $\mathrm{Zn}_{2} \mathrm{TiO}_{4}$ and $\mathrm{ZnO}$ on the surface of $\mathrm{B} 1$, which reduces the wear during the friction process. Samples C1 and D1 started to crystallize and form a composite phase composed of $\mathrm{Zn}_{4} \mathrm{TiO}_{6}$ and $\mathrm{Ti}_{3} \mathrm{O}_{5}$. It did not provide good lubrication. When the sliding distance increases to $10 \mathrm{~m}$, the friction coefficient of the $\mathrm{C} 1 \mathrm{film}$ starts to increase sharply. After a sliding distance of $4 \mathrm{~m}$, the friction factor of the D1 film increases. This can be attributed to the low crystallinity of the D1 film. At this stage, the film may gradually wear through. 
Table 4 The wear rate of as-deposited and annealed films.

\begin{tabular}{cccc}
\hline The original & wear rate $\left(10^{-5} \mathrm{~mm}^{3} / \mathrm{N} \cdot \mathrm{m}\right)$ & Annealed & wear rate $\left(10^{-5} \mathrm{~mm}^{3} / \mathrm{N} \cdot \mathrm{m}\right)$ \\
\hline A & $0.74(100 \mathrm{~m})$ & A1 & $7.2(100 \mathrm{~m})$ \\
B & $18(18 \mathrm{~m})$ & B1 & $9(65 \mathrm{~m})$ \\
C & $25(18 \mathrm{~m})$ & C1 & $7.4(50 \mathrm{~m})$ \\
D & $7.2(18 \mathrm{~m})$ & D1 & $22(6 \mathrm{~m})$
\end{tabular}

The surface morphology and the 2D images of the original film wear scar are shown in Fig. 10 and Fig.11. It can be seen from the figure that different films have different sliding distance ranges. The film of A is $100 \mathrm{~m}$, $\mathrm{B}, \mathrm{C}$ and $\mathrm{D}$ are all $18 \mathrm{~m}$. The depth of wear scars in different grinding passes is $1.5 \mu \mathrm{m}, 1.4 \mu \mathrm{m}, 1.1 \mu \mathrm{m}$, and $1.1 \mu \mathrm{m}$. The width is about $40 \mu \mathrm{m}, 125 \mu \mathrm{m}, 70 \mu \mathrm{m}$, and $30 \mu \mathrm{m}$, respectively. In a sliding distance of $100 \mathrm{~m}$, the friction surface of sample A was smooth. A flaky accumulation of debris was produced when sample B rubbed on the surface. It could be because of the increase in the contact area between the film and the dual ball, and deformation occurs when subject to the squeezing force. The surface layer material is primarily composed of the composite phase of $\mathrm{Zn}_{2} \mathrm{TiO}_{4}, \mathrm{ZnO}$, and $\mathrm{TiO}_{2}$ does not provide good lubrication, instead acts serve the role of grinding. The wear is accelerated by the continuous plowing of the surface by the particles. Resultantly, the wear mechanism of the wear scars is severely abrasive wear. The surface hardness is relatively high in the amorphous samples $\mathrm{C}$ and $\mathrm{D}$. The film will not easily fall off during the friction process. Therefore, the friction surface is primarily ploughing wearing.

The surface morphology and 2D images of the wear traces of the annealed films are shown in Fig.12 and Fig.13, respectively. Sample A1 has a depth of 4 um and

(a)

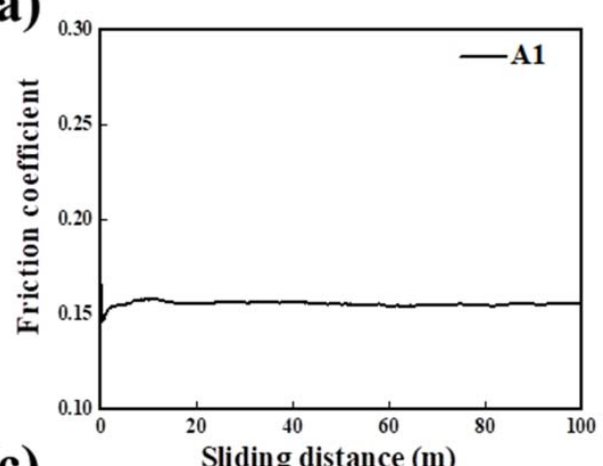

(c)

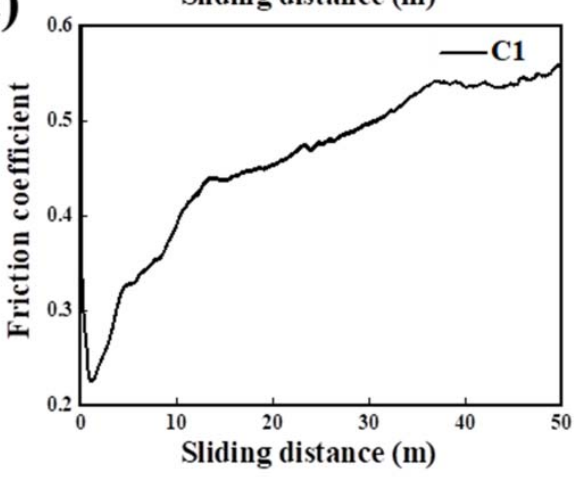

a width of $45 \mu \mathrm{m}$ in a $100 \mathrm{~m}$ grinding pass. Sample B1 has a depth of $1.7 \mu \mathrm{m}$ and a width of $175 \mu \mathrm{m}$ in a $65 \mathrm{~m}$ grinding pass. The wear depth of sample $\mathrm{C} 1$ at a sliding distance of $50 \mathrm{~m}$ is $1.6 \mu \mathrm{m}$, and the width is $137 \mu \mathrm{m}$. The wear depth of sample D1 at a sliding distance of $18 \mathrm{~m}$ is $1 \mathrm{um}$, and the width is $92 \mu \mathrm{m}$. The friction surface of the annealed film Al is smooth. The resulting $\mathrm{ZnTiO}_{3}$ composite phase provides good lubricating effects. In the white boxes in Figure 12 (b) and (c), fish scales appear on the friction surfaces of films B1 and C1. This could be due to the partial peeling of the film during the friction process because of the small hardness. So, the wear scars widen quickly. According to EDS analysis, the fish scale-like material contains oxygen, titanium, zinc and very little aluminum. This implies the occurrence of material transfer. The compositions of the surfaces of the films $\mathrm{B} 1$ and $\mathrm{C} 1$ contain $\mathrm{Zn}_{2} \mathrm{TiO}_{4}, \mathrm{ZnO}$ composite phase and $\mathrm{Zn}_{4} \mathrm{TiO}_{6}, \mathrm{Ti}_{3} \mathrm{O}_{5}$ composite phase, respectively. Even though the film peeled off, the peeled material filled the peeling pit. As a result, the wear rate of the film has not been greatly reduced, and the friction surface primarily exhibits features of adhesive wear. Once the sliding distance exceeded $6 \mathrm{~m}$, the friction test was stopped, because after $4 \mathrm{~m}$, the friction factor of D1 increased sharply. Therefore, the friction surface displays features of abrasive wear.
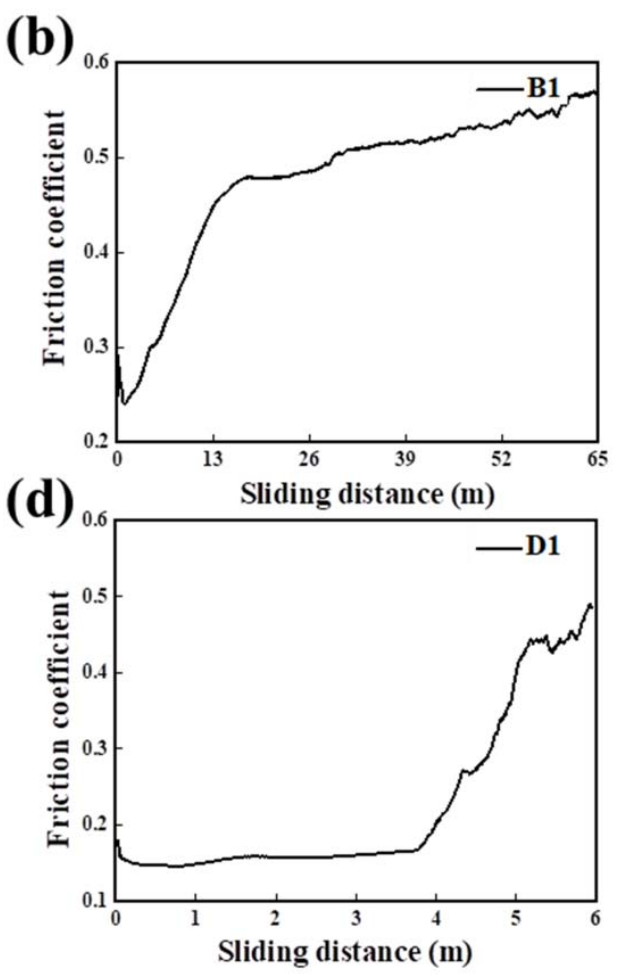

Fig. 9. The change curve of friction coefficient with a sliding distance of annealed films 

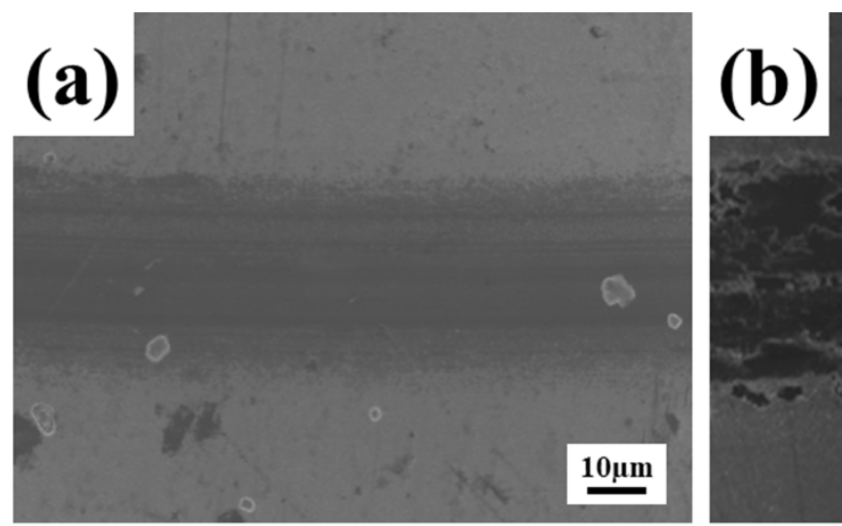

(c)

\section{(d)}

Fig. 10. The worn surface morphology

(a)

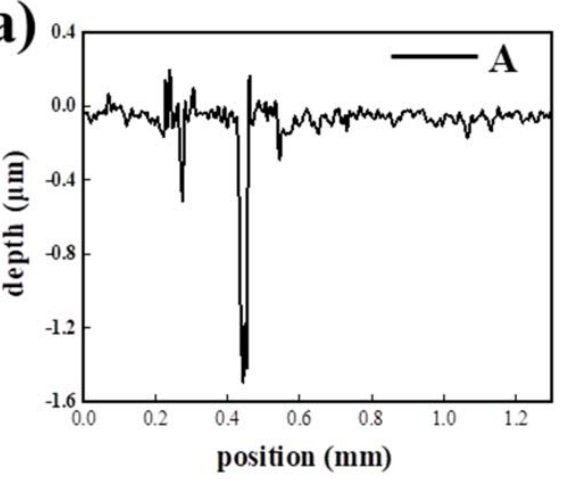

(c)

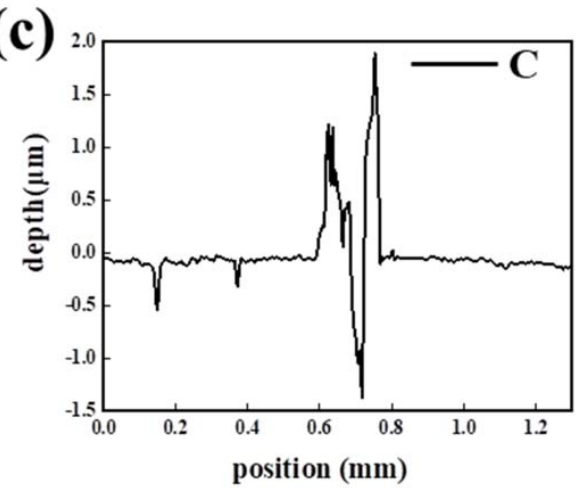

(b)

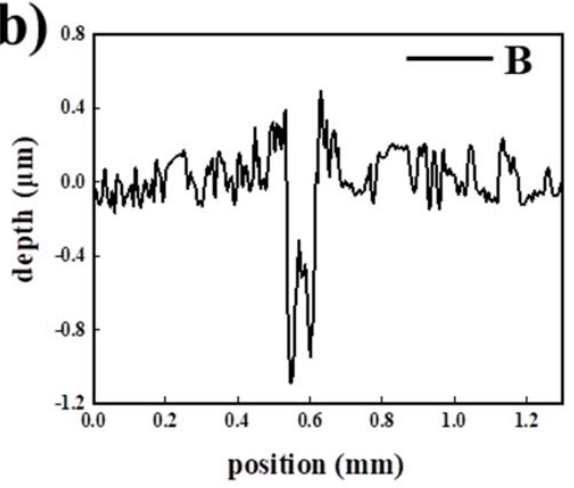

(d)

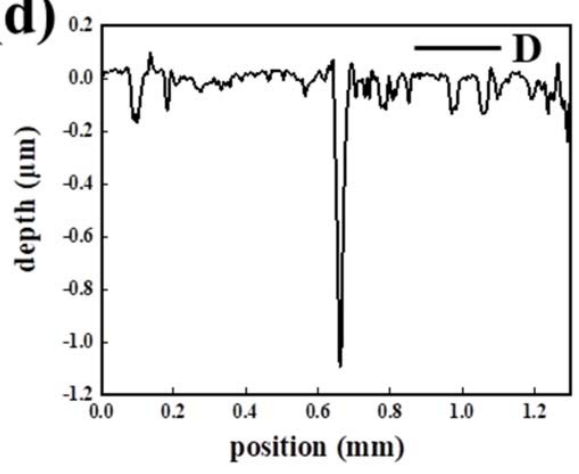

Fig. 11. The 2D images of as-deposited films 

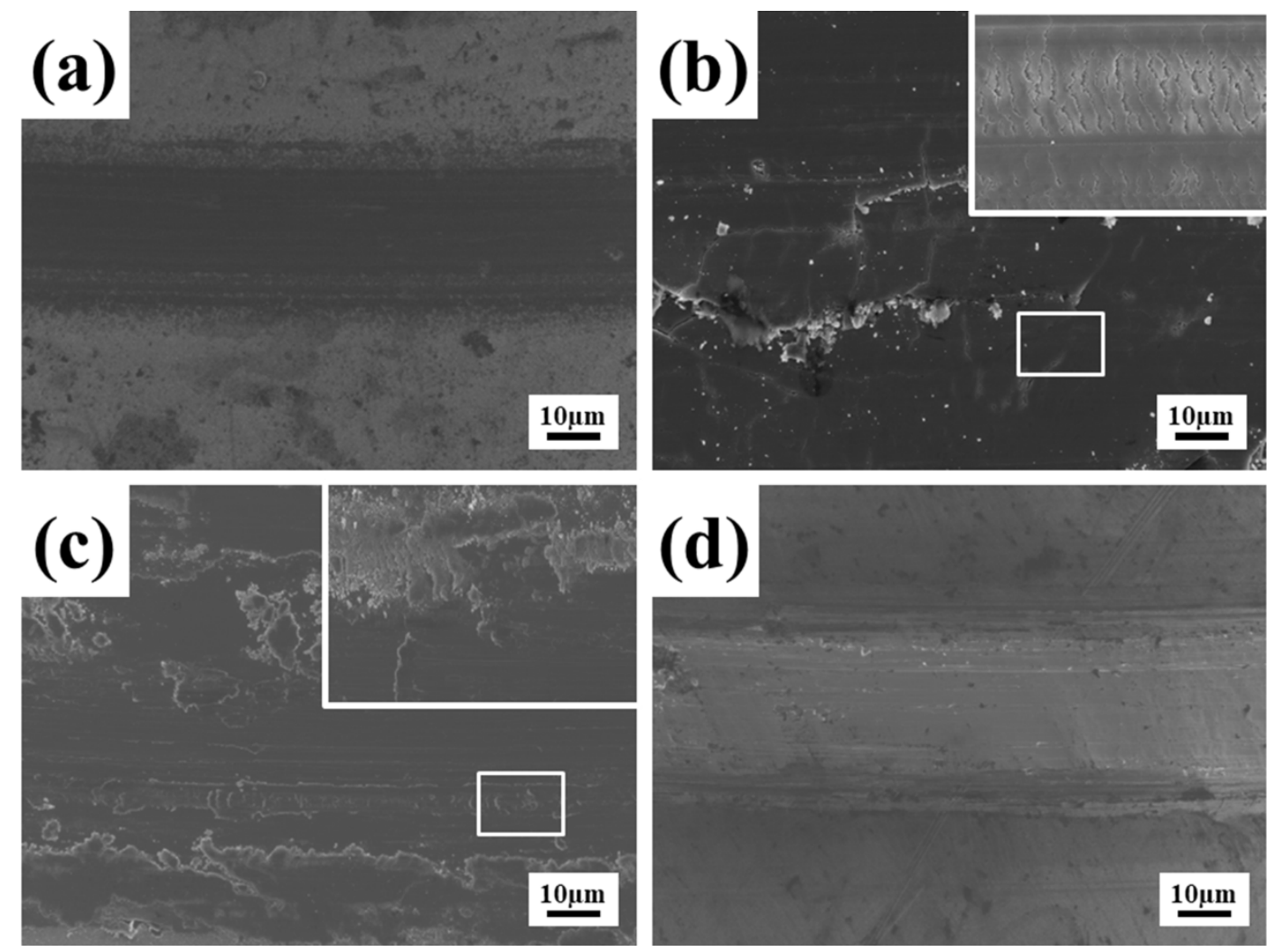

\section{(d)}

Fig. 12. The worn surface morphology

(a)

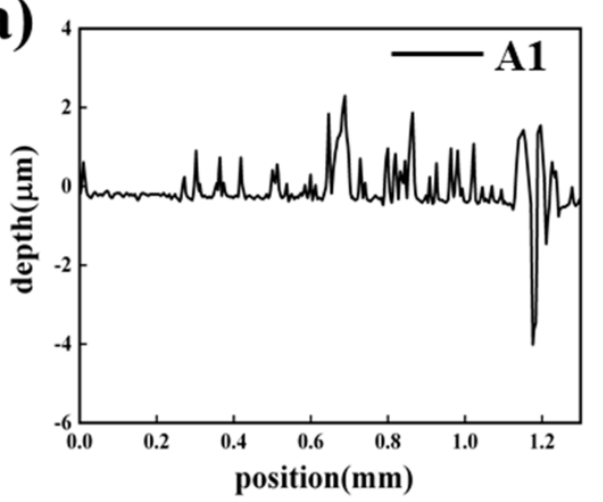

(c)

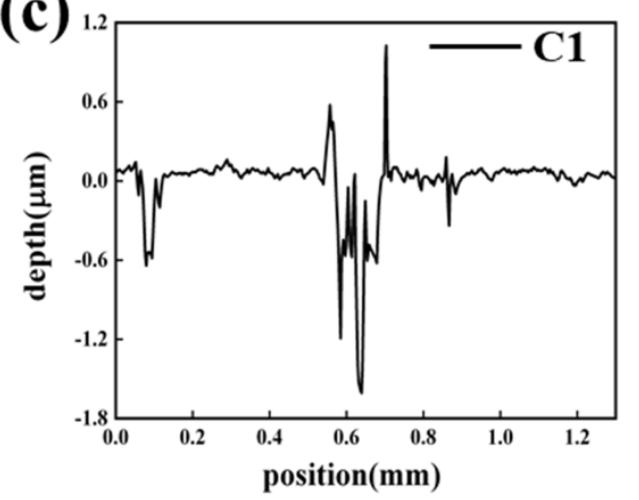

(b)

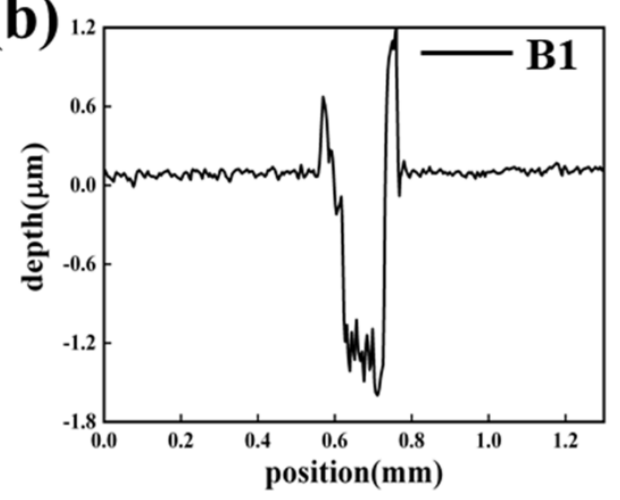

(d)

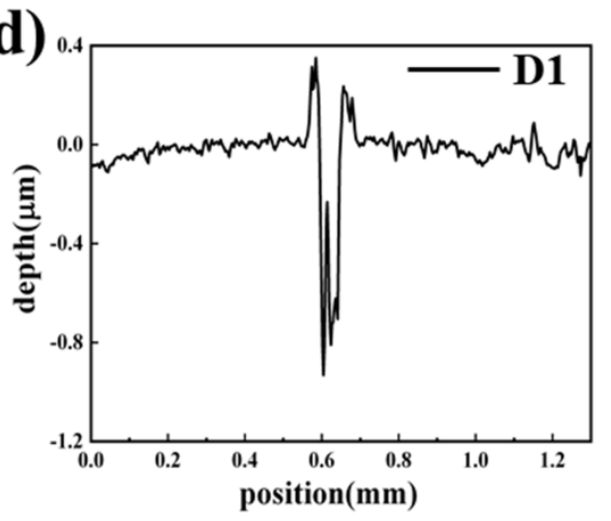

Fig. 13. The 2D images of annealed films

\section{Conclusion}

The films deposited by multi-arc ion plating technology contain large particles of different shapes and sizes. In addition to affecting the smoothness of the film surface, such particles also affect the overall performance of the film. Therefore, in this paper, magnetron sputtering technology was used to prepare $\mathrm{Zn}$ and $\mathrm{Ti}$ series bimetallic oxide films on the surface of Inconel 718 substrate. Following the preparation, the films were annealed at a high temperature of $600{ }^{\circ} \mathrm{C}$. The structure, 
morphology, mechanical properties, and tribological properties of the films before and after annealing were studied. The main conclusions of this study are as follows:

(1) The surface quality of the film prepared by magnetically controlled sputtering technology is superior. It has no defects, such as large particles, droplets, micropores, etc. During the process of thin-film deposition, firstly, Titanium atoms form stable nuclei, and the Titanium nuclei continually absorb the surrounding atoms to create small islands, following which, larger islands are formed. Ultimately, the large islands grow and fuse with each other into thin films. Therefore, as the content of $\mathrm{Zn}$ in the film decreases, the density of the film surface increases. The composite phase of $\mathrm{ZnTiO}_{3}$ and $\mathrm{ZnO}$ was formed on the surface of film A. The composite phase of $\mathrm{Zn}_{2} \mathrm{TiO}_{4}, \mathrm{ZnO}$ and $\mathrm{TiO}_{2}$ was formed on the surface of film B. Due to the large deposition rate of Titanium atoms, the particles were unable to reach the surface of the substrate to migrate. So, the surface of the thin films $\mathrm{C}$ and $\mathrm{D}$ contained an amorphous structure. Following the annealing process, different composite phases of $\mathrm{Zn}_{\mathrm{x}} \mathrm{Ti}_{\mathrm{y}} \mathrm{O}_{\mathrm{z}}, \mathrm{ZnO}$ and $\mathrm{TiO}_{2}$ were formed on the surface of the film. The small crystal nucleus formed by the original thin film after annealing treatment grows up, and the thin film without crystal also gradually forms crystals with lower crystallinity. As the $\mathrm{Zn}$ content decreases, the grains become increasingly smaller, and the surface structure of the film becomes denser.

(2) As the content of $\mathrm{Zn}$ decreased and the content of $\mathrm{Ti}$ increased in the original film, the number of stable nuclei increased, and the number of Zinc atoms surrounding the crystal nuclei decreased. As a result, the grain size of the thin film decreased, and the film hardness and bonding strength of the film base increased. As the content of $\mathrm{Zn}$ continued to decrease, the atoms in the film were disorderly arranged without any grain boundaries. So, the mechanical properties of the film were excellent. When the $\mathrm{Zn}$ element content was $28.01 \mathrm{wt} \%$ and the Ti content was $12.59 \mathrm{wt} \%$, the film hardness was $417.7 \mathrm{HV}$, and the film substrate-binding force was $35.9 \mathrm{~N}$. Following the annealing process at $600{ }^{\circ} \mathrm{C}$, the grains exhibited growth, and the hardness and bonding force was less than those of the original film. When the $\mathrm{Zn}$ content was $28.49 \mathrm{wt} \%$ and the Ti content was $14.31 \mathrm{wt} \%$, the maximum hardness of the film was $382.5 \mathrm{HV}$, and the film base binding force was $18 \mathrm{~N}$.

(3) The film of A exhibited excellent tribological properties within a sliding distance of $100 \mathrm{~m}$. These properties can be attributed to the formation of a lubricating composite phase of $\mathrm{ZnTiO}_{3}$ and $\mathrm{ZnO}$ on the surface of film A. As the content of $\mathrm{Zn}$ decreases, the friction coefficient and wear rate of the original film increased rapidly within a small grinding interval. The wear-through phenomenon occurred in different sliding distance ranges.

\section{References}

1. T. W. Scharf, S. V. Prasad. Solid lubricants: a review.
Journal of Materials Science. 2013; 48:511-531.

2. H. P. Xiao, S. H. Liu, D. X. Han, et al. Effects of physically deposited multilayer graphene platelet and graphite on tribological performance of alumina on alumina contact. Proceedings of the Institution of Mechanical Engineers, Part J: Journal of Engineering Tribology,2019,233(1).

3. F. Li, J Cheng, S.Y. Zhu, et al. Microstructure and mechanical properties of Ni-based high temperature solid-lubricating composites. Materials Science and Engineering: A. 2017; 682:475-481.

4. W. Deng, X. Q. Zhao, Y. L. An, et al. Study on preparation and tribological properties of as-sprayed 8YSZ/Graphite coating. Surface Engineering. 2019; 133: 206-223.

5. S.Y. Zhu, J. Chen, Z.H. Qiao, et al. High temperature solid-lubricating materials: A review. Tribology International. 2019; 133:206-223.

6. SD Walck, JS Zabinski, MS Donley, et al. Characterization of pulsed laser deposited $\mathrm{PbO} / \mathrm{MoS}_{2}$ by transmission electron microscopy. Journal of Materials Research. 1994; 9:236-245.

7. F.A. Essa, Q.X. Zhang, X.J. Huang. Investigation of the effects of mixtures of $\mathrm{WS}_{2}$ and $\mathrm{ZnO}$ solid lubricants on the sliding friction and wear of M50 steel against silicon nitride at elevated temperatures. Wear. 2017; 374-375: 128-141.

8. A.V. Bondarev, E.A. Levashov, D.V. Shtansky et al. Tribological behavior and self-healing functionality of TiNbCN-Ag coatings in wide temperature range. Applied Surface Science. 2017; 396: 110-120.

9. H.J. Mei, Q.S. Luo, X.L. Huang et al. Influence of lubricious oxides formation on the tribological behavior of $\mathrm{Mo}-\mathrm{V}-\mathrm{Cu}-\mathrm{N}$ coatings deposited by HIPIMS. Surface and Coatings Technology. 2019; 358: 947-957.

10. X. Dai, M. Wen, K. K. Huang. Toward low friction in water for $\mathrm{Mo}_{2} \mathrm{~N} / \mathrm{Ag}$ coatings by tailoring the wettability. Applied Surface Science.2018;447:886-893.

11. Y.Q. Zhao, Y.T. Mu, M. Liu. Mechanical properties and friction-wear characteristics of $\mathrm{VN} / \mathrm{Ag}$ multilayer coatings with heterogeneous and transition interfaces. Transactions of Nonferrous Metals Society of China.2020;30:472-483.

12. Y.P. Purandare, G.L. Robinson, A.P. Ehiasarian et al. Investigation of High Power Impulse Magnetron Sputtering deposited nanoscale $\mathrm{CrN} / \mathrm{NbN}$ multilayer coating for tribocorrosion resistance. Wear.2020;452-453.

13. J.H. Hsieh, C.H. Chiu, C. Li, et al. Development of anti-wear and anti-bacteria $\mathrm{TaN}-(\mathrm{Ag}, \mathrm{Cu})$ thin films - a review. Surface and Coatings Technology. 2013; 233: 159-168.

14. S.M. Aouadi, D.P. Singh, D.S. Stone et al. Adaptive VN/Ag nanocomposite coatings with lubricious behavior from 25 to $1000{ }^{\circ} \mathrm{C}$. Acta Materialia 2010; 58: 5326-5331.

15. W. Gulbiński, T. Suszko. Thin films of $\mathrm{Mo}_{2} \mathrm{~N} / \mathrm{Ag}$ nanocomposite-the structure, mechanical and tribological properties. Surface and Coatings 
Technology. 2006;201:1469-1476.

16. H. J. Guo, C. Lu, Z. Y. Zhang, et al. Comparison of microstructures and properties of $\mathrm{VN}$ and $\mathrm{VN} / \mathrm{Ag}$ nanocomposite films fabricated by pulsed laser deposition. Applied Physics A. 2018; 124:694.

17. H.B. Ju, J.H. Xu. Microstructure and tribological properties of $\mathrm{NbN}-\mathrm{Ag}$ composite films by reactive magnetron sputtering. Applied Surface Science. 2015;355:878-883.

18. D.S. Stone, H.Y. Gao, C. Chantharangsi, et al. Reconstruction mechanisms of tantalum oxide coatings with low concentrations of silver for high temperature tribological applications. Applied Physics Letters. 2014;105:191607-191607.

19. V. Ageh, H. Mohseni, T.W. Scharf. Lubricious zinc titanate coatings for high temperature applications. Surface and Coatings Technology. 2013;237:241-247.

20. N.R. He, H.X. Li, J. Li, et al. Reusable chromium oxide coating with lubricating behavior from 25 to $1000{ }^{\circ} \mathrm{C}$ due to a self-assembled mesh-like surface structure. Surface and Coatings Technology.2017;321:300-308.

21. J.H.E. Jeffes. Ellingham Diagrams. Encyclopedia of Materials: Science and Technology. 2001:2751-2753.

22. A.W, Burton, K. Ong, T. Rea, et al. On the estimation of average crystallite size of zeolites from the Scherrer equation: A critical evaluation of its application to zeolites with one-dimensional pore systems. Microporous and Mesoporous Materials. 2009;117:75-90.

23. V. Ageh, H. Mohseni, T .W. Scharf. Processingstructure-tribological property interrelation- ships of zinc titanate coatings grown by atomic layer deposition. Surface and Coatings Technology.2014; 241:112-117.

24. S.M. Aouadi, H. Gao, A. Martini, et al. Lubricious oxide coatings for extreme temperature applications: A review. Surface and Coatings Technology. 2014; 257:266-277. 